\title{
Prevalence and Determinants of Vaginal Infection With Human Papillomavirus Among Female University Students in Vietnam
}

\author{
NGUYEN VAN TRANG ${ }^{1 *}$, KIESHA PREM ${ }^{2 *}$, ZHENG QUAN TOH ${ }^{3,4}$, BUI THI VIET HA ${ }^{5}$, PHAM THI NGOC LAN ${ }^{6}$, \\ HAU PHUC TRAN ${ }^{7}$, QUANG DUY PHAM ${ }^{7}$, NGHIA VAN KHUU ${ }^{7}$, MARK JIT ${ }^{2,8,9}$, DUNG THI LUU ${ }^{10}$, \\ LE THI KHANH LY ${ }^{1}$, VAN CAO ${ }^{7}$, TAM-DUONG LE-HA ${ }^{7}$, KATHRYN BRIGHT ${ }^{3}$, \\ SUZANNE M. GARLAND ${ }^{3,11,12}$, DANG DUC ANH ${ }^{1 \#}$ and KIM MULHOLLAND ${ }^{2,3,4 \#}$ \\ ${ }^{1}$ National Institute of Hygiene and Epidemiology, Hanoi, Vietnam; \\ ${ }^{2}$ Department of Infectious Disease Epidemiology, London School of Hygiene and Tropical Medicine, London, U.K.; \\ ${ }^{3}$ Infection and Immunity, Murdoch Children's Research Institute, Parkville, Victoria, Australia; \\ ${ }^{4}$ Department of Paediatrics, The University of Melbourne, Parkville, Victoria, Australia; \\ ${ }^{5}$ Department of Microbiology, University of Science, Vietnam National University, Hanoi, Vietnam; \\ ${ }^{6}$ Department of Natural Science, Vietnam National University of Hue, Hue, Vietnam; \\ ${ }^{7}$ Pasteur Institute of Ho Chi Minh City, Ho Chi Minh City, Vietnam; \\ ${ }^{8}$ School of Public Health, University of Hong Kong, Hong Kong, SAR, P.R. China; \\ ${ }^{9}$ Public Health England, Modelling and Economics Unit, London, U.K.; \\ ${ }^{10}$ National Institute for Control of Vaccines and Biologicals, Hanoi, Vietnam; \\ ${ }^{11}$ Centre for Women's Infectious Diseases, The Royal Women's Hospital, Parkville, Victoria, Australia; \\ ${ }^{12}$ Department of Obstetrics and Gynecology, The University of Melbourne, Parkville, Victoria, Australia
}

\begin{abstract}
Background/Aim: Cervical cancer is the second most common malignancy among women in Vietnam, but the country is yet to introduce a national human papillomavirus $(H P V)$ vaccine programme targeted at adolescents. We determined HPV prevalence and HPV vaccine knowledge among female university students in Vietnam. Patients and Methods: We surveyed and screened 1,491 female university students in Hanoi, Hue, and Ho Chi Minh City for their sexual behaviours, HPV knowledge and low-and high-risk HPV infection. Results: The prevalence of any HPV infection and any high-risk HPV infection were 4.2\% (95\% CI=3.3\%-
\end{abstract}

This article is freely accessible online.

\footnotetext{
*These Authors contributed equally to the study.

\#Equal corresponding Authors.
}

Correspondence to: Prof. Kim Mulholland, Murdoch Children's Research Institute, Royal Children's Hospital, Flemington Road, Parkville, Victoria 3052 Australia. Tel: +61 399366656, Fax: +61 393481391, e-mail: kim.mulholland@mcri.edu.au and Prof. Dang Duc Anh, National Institute of Hygiene and Epidemiology, 1 Yersin Street, Hai Ba Trung, Hanoi, Vietnam. Tel: +84 439716356, Fax: +84 2438210853, e-mail: dda@nihe.org.vn

Key Words: Human papillomavirus, female, prevalence, university students, Vietnam.
$5.4 \%)$ and $3.4 \%(95 \% C I=2.5 \%-4.4 \%)$, respectively. Being sexually active [adjusted prevalence ratio (aPR): 6.22; 95\%CI=3.4-11.37] and having ever been pregnant (aPR: 4.82; 95\%CI=1.93-12.04) were positively associated with high-risk HPV infection. Whilst $60 \%$ of participants had heard of HPV vaccine, only $4.6 \%$ had received the vaccine. Conclusion: The low HPV prevalence found in university students in Vietnam indicates that they can benefit from HPV vaccination, along with a well-designed HPV health promotion programme.

Human papillomavirus (HPV) is one of the most common sexually transmitted infections around the world (1). It is the cause of several types of anogenital cancers and oropharyngeal cancer, of which the most common is cervical cancer. The majority of HPV infections (80\%) are asymptomatic and resolve spontaneously. For those women with persistent infections with high-risk (hr) or oncogenic HPV genotypes, a proportion may later develop cervical abnormalities of high-grade cervical dysplasias which are precursors to cancer (2-5).

To date, three licensed prophylactic HPV vaccines are available, all of which target HPV 16 and 18 which are responsible for approximately $70 \%$ of cervical cancer cases globally. The nonavalent HPV vaccine also protects against an additional five common cancer-causing HPV types (HPV31, 33, 45, 52 and 58) responsible for another $20 \%$ of 
cervical cancer cases worldwide (6). The World Health Organization (WHO) recommends that all countries vaccinate at least $90 \%$ of females aged 9-14 years against HPV. This is a key component of the 2030 goal of $90 \%, 70 \%$ and $90 \%$ for vaccination, screening and treatment respectively to establish the basis for the global elimination of cervical cancer as a public health matter (7-11). Although cervical screening with high precision tests at 35 and 45 years of age has been successful in detecting hrHPV types predicting underlying cancer precursors, such secondary prevention has several challenges, including difficulties in implementing these procedures at high coverage levels in many low- and middle-income countries (LMICs) where appropriate infrastructure may be lacking $(7,12)$.

Cervical cancer is the second most common malignancy among women in Vietnam $(13,14)$. However, the country has not yet introduced a national HPV vaccination programme, even though HPV vaccination of young adolescent females has been shown to be cost-effective in Vietnam (15). Young women who have recently become sexually active are at high risk of acquiring HPV infection (16). Low HPV vaccination rates among young girls (9-18 years old) predisposes them to HPV infection as they reach sexual maturity $(4,11,17,18)$. In this cross-sectional study, we measured the HPV infection rates and the risk factors for HPV infection, as well as HPV disease and HPV vaccination knowledge among female university students from three universities in Hanoi, Hue and Ho Chi Minh City (HCMC), Vietnam.

\section{Patients and Methods}

Participants. Cross-sectional surveys of HPV genoprevalence, risk factors and knowledge among university students were conducted from November 2017 to March 2019 in three major Vietnamese cities: Hanoi in northern Vietnam, Hue in central Vietnam, and HCMC in southern Vietnam. Most undergraduate students in Vietnam take 4-5-year degree courses with the university calendar starting in September and ending in June of the following year. The majority of students start university at 18 years of age. Participants in this study were first- and fourth-year university students from selected universities in Hanoi, Hue and HCMC. Recruitment began in Hanoi (November 2017), continued in Hue (December 2017), and ended in HCMC (December 2018-March 2019). Students from all departments in the universities were recruited; the departments were then categorized into social and natural science. Although universities in Hanoi and Hue have both departments, the university in HCMC only has the department of natural science. Participants were recruited via social media platforms such as Facebook, Zalo and Instagram, as well as through the student union. Participants were recruited on a first-come-first-serve basis while ensuring the number of students from the first year and fourth year were roughly equal. A total of 1,500 female students were determined eligible and provided consent to participate in this study. Based on an estimated HPV prevalence of 4-20\% among girls aged 18-24 years in Vietnam, a total of 245 participants/group/site is needed to achieve
$80 \%$ power. Thus, we aimed to recruit 500 participants from year 1 and year 4 from each university.

Outcome assessments. In a private room at each university, students received instructions by trained medical staff on self-collection of vaginal samples for HPV screening. After sampling, the students were invited to complete a questionnaire lasting approximately 20 min. A trained interviewer asked the participants basic questions about their demographic attributes, sexual behaviours, HPV vaccination status, medical history and knowledge of HPV and its prevention. Participants were given the option to complete questions on their sexual behaviour by themselves. Any participants found to be positive for HPV16/18 were referred to further gynaecological examination and management.

HPV detection and genotyping test. HPV detection and genotyping were performed in two steps. Firstly, nucleic acid extraction was performed using Cador pathogen 96 Qiacube HT kit (Qiagen, Hilden, Germany) on an automated platform, followed by amplification with PGMY9/11 system by polymerase chain reaction (PCR) (19). Next, the positive samples by PCR were subjected to genotyping by Geneflow HPV array test kit (Diagcor, Hong Kong), which allows detection and identification of 33 HPV types [14 highrisk (hr), three probable high-risk and 16 low-risk types]. The kit was in-vitro diagnostic and qualified annually by WHO for hrHPV detection and classification.

The human leukocyte antigen (HLA) and beta-globulin genes were used as internal controls for the PGMY9/11 PCR and Geneflow kit, respectively. The HLA primer pair are directed against the common site of all HLA types. Samples that were negative for the HLA gene were considered invalid, and the participants were asked to return for a new sample collection. Method validation was done on a panel of 40 previously tested samples prior to the screening test. External quality control was also performed by the Western Pacific WHO reference laboratory for HPV at the Royal Women's Hospital, University of Melbourne, Australia. We found $\sim 90 \%$ agreement for hrHPV between laboratories for all samples; some discordant/missed results were found for certain tested hrHPV genotypes: 4/20 for HPV16, 1/12 for HPV 18, 1/4 for HPV31, 2/12 for HPV39, 2/7 for HPV45, 3/9 for HPV56, 2/17 for HPV58, 3/16 for HPV 66.

Statistical analysis. Thirty-three HPV genotypes were analysed including (i) high-risk: 16, 18, 31, 33, 35, 39, 45, 51, 52, 56, 58, $59,66 / 68$; or (ii) low-risk: $6,11,26,40,42,43,44,53,54,55,57$, $61,70,71,72,73,81,82$. We calculated the prevalence of any, high-risk, and low-risk HPV infections. To compare the sociodemographic, behavioural, and knowledge variables, we employed a Chi-square test (or Fisher's exact test) for categorical variables, and Student's $t$-test or Mann-Whitney $U$-test for continuous variables, as appropriate. We explored the bivariate relationship between HPV infection and possible explanatory variables such as college field, year of study, and city. A multivariable modified Cox regression was performed to determine risk factors-participants' socio-demographics, sexual behaviours, medical history, HPV knowledge - that were correlated with high-risk HPV infection at time of screening. Initially, variables with a significance level of $p<0.10$ in the bivariate modified Cox regression were included in the multivariable model. A likelihood ratio test was then used to compare the goodness of fit of the nested models. We obtained 
Table I. Participants' demographic and behavioural characteristics by city in Vietnam.

\begin{tabular}{|c|c|c|c|c|}
\hline Demographics & Hanoi $(\mathrm{N}=492)$ & Hue $(\mathrm{N}=499)$ & $\operatorname{HCMC}(\mathrm{N}=500)$ & Total \\
\hline \multicolumn{5}{|l|}{ Age, in years } \\
\hline Mean (SD) & $19.7(1.6)$ & $19.9(1.7)$ & $19.9(1.5)$ & $19.8(1.6)$ \\
\hline Median (range) & $21(18-24)$ & $21(18-26)$ & $20(18-25)$ & $21(18-26)$ \\
\hline Kinh ethnicity, n (\%) & $385(78.3)$ & $435(87.2)$ & $486(97.2)$ & $1,306(87.6)$ \\
\hline \multicolumn{5}{|l|}{ College field, n (\%) } \\
\hline Natural sciences & $286(58.1)$ & $195(39.1)$ & $500(100)$ & $981(65.8)$ \\
\hline Social sciences & 206 (41.9) & $304(60.9)$ & $0(0)$ & $510(34.2)$ \\
\hline \multicolumn{5}{|l|}{ Year in college, $\mathrm{n}(\%)$} \\
\hline Year 1 & $245(49.8)$ & $242(48.5)$ & $251(50.2)$ & $738(49.5)$ \\
\hline Year 4 & $247(50.2)$ & $257(51.5)$ & $249(49.8)$ & $753(50.5)$ \\
\hline Ever married, n (\%) & $1(0.2)$ & $4(0.8)$ & $0(0)$ & $5(0.3)$ \\
\hline \multicolumn{5}{|l|}{ Living arrangements, $\mathrm{n}(\%)$} \\
\hline With family & $122(24.8)$ & $196(39.3)$ & $193(38.6)$ & $511(34.3)$ \\
\hline With friends & $346(70.3)$ & $168(33.7)$ & $300(60)$ & $814(54.6)$ \\
\hline Alone & $24(4.9)$ & $135(27.1)$ & $7(1.4)$ & $166(11.1)$ \\
\hline \multicolumn{5}{|l|}{ Behaviour } \\
\hline Ever smoked, n (\%) & $15(3)$ & $6(1.2)$ & $5(1)$ & $26(1.7)$ \\
\hline Ever consumed alcohol, n (\%) & $333(67.7)$ & $346(69.3)$ & $332(66.4)$ & $1,011(67.8)$ \\
\hline Ever had sex, n (\%) & $64(13)$ & $94(18.8)$ & $44(8.8)$ & $202(13.5)$ \\
\hline Age of sex debut, in years, median (range) & $20(16-23)$ & $20(15-23)$ & $18(14-22)$ & $19(14-23)$ \\
\hline Number of sex partners, median (range) & $1(1-7)$ & $1(1-3)$ & $1(1-3)$ & $1(1-7)$ \\
\hline \multicolumn{5}{|l|}{ Type of sex } \\
\hline Oral & $1(0.2)$ & $5(1)$ & $1(0.2)$ & $7(0.5)$ \\
\hline Vaginal & $60(12.2)$ & $88(17.6)$ & $42(8.4)$ & $190(12.7)$ \\
\hline Anal & $0(0)$ & $0(0)$ & $0(0)$ & $0(0)$ \\
\hline Inconsistent contraceptive use, $\mathrm{n}(\%)$ & $34(6.9)$ & $51(10.2)$ & $22(4.4)$ & $107(7.2)$ \\
\hline Inconsistent condom use & $14(2.8)$ & $33(6.6)$ & $6(1.2)$ & $53(3.6)$ \\
\hline Ever pregnant, n $(\%)$ & $5(1)$ & $6(1.2)$ & $1(0.2)$ & $12(0.8)$ \\
\hline Ever given birth, n (\%) & $1(0.2)$ & $3(0.6)$ & $0(0)$ & $4(0.3)$ \\
\hline Ever had abortion, n (\%) & $4(0.8)$ & $4(0.8)$ & $1(0.2)$ & $9(0.6)$ \\
\hline Ever had any gynaecological infections, $\mathrm{n}(\%)$ & $60(12.2)$ & $156(31.3)$ & $26(5.2)$ & $242(16.2)$ \\
\hline \multicolumn{5}{|l|}{ HPV infection, $\mathrm{n}(\%)$} \\
\hline Any HPV infection & $25(5.1)$ & $32(6.4)$ & $6(1.2)$ & $63(4.2)$ \\
\hline High-risk HPV infection & $20(4.1)$ & $24(4.8)$ & $6(1.2)$ & $50(3.4)$ \\
\hline Low-risk HPV infection & $2(0.4)$ & $6(1.2)$ & $0(0)$ & $8(0.5)$ \\
\hline \multicolumn{5}{|l|}{ Knowledge of HPV and HPV vaccine, $\mathrm{n}(\%)$} \\
\hline Ever heard of HPV & $345(70.1)$ & $434(87)$ & $318(63.6)$ & $1,097(73.6)$ \\
\hline Ever heard of HPV vaccine & $259(52.6)$ & $310(62.1)$ & $348(69.6)$ & $917(61.5)$ \\
\hline Ever had HPV vaccine & $14(2.8)$ & $9(1.8)$ & $45(9)$ & $68(4.6)$ \\
\hline Family history of HPV infection & $7(1.4)$ & $4(0.8)$ & $15(3)$ & $26(1.7)$ \\
\hline
\end{tabular}

N: Sample size; n: frequency; SD: standard deviation; HCMC: Ho Chi Minh city.

adjusted prevalence ratios (aPR) for all comparisons and presented them with the $95 \%$ confidence intervals (CIs). All data analyses were conducted in $\mathrm{R}$.

Ethics approval and consent to participate. Institutional Review Boards of the National Institute of Hygiene and Epidemiology, Vietnam (reference number: IRB-VN01057-13/2017) and the ethics board of the London School of Hygiene and Tropical Medicine (reference number: 14207) approved this study. To protect the confidentiality and privacy of the study participants, we replaced personal identifiers from any documents with barcodes and collected data and samples from the participants in private places. Eligible participants were informed of the nature of the study including the risks and benefits they may expect, and the way their data would be used. Written informed consent was obtained from all participants.

Test results were communicated with the participants when available. Any participants found to be positive for HPV 16/18 were referred to further gynaecological examination and management.

\section{Results}

Participant's characteristics. A total of 1,500 participants were recruited, with no refusal. Nine students (eight in Hanoi and one in Hue) did not provide sufficient samples (negative for HLA gene), thus their data were excluded from all analyses. The demographic characteristics of the 1,491 

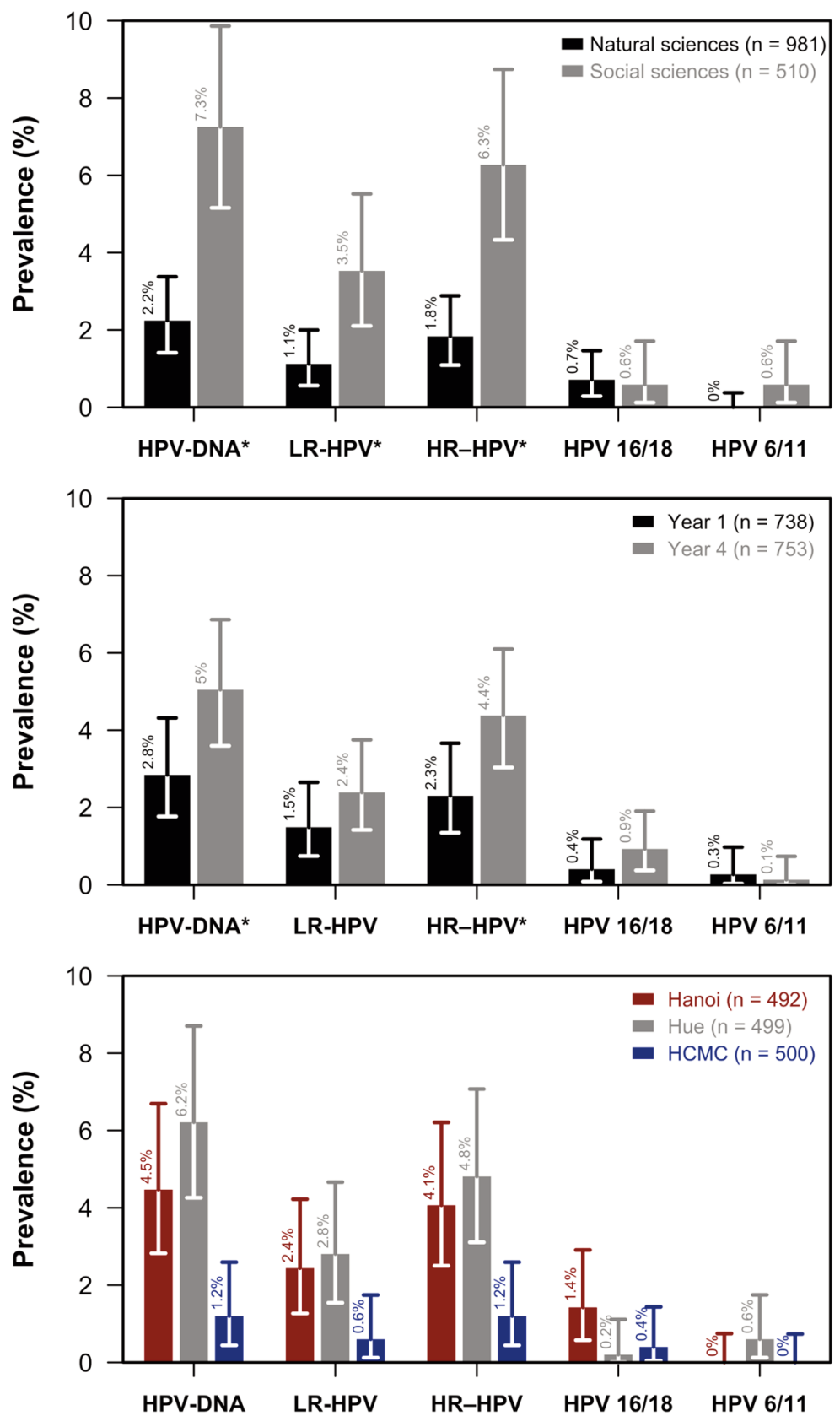

Figure 1. Prevalence of HPV infection among female university students in Hanoi, Hue, and Ho Chi Minh City by college field, year of study, and city. Natural science major/first year (black) and social science major/fourth year (grey) students in the upper and middle panel, respectively; and north Vietnam, Hanoi (red), central Vietnam, Hue (grey) and south Vietnam, Ho Chi Minh (blue) in the lower panel. The high-risk (hr) HPV types include 16, 18, 31, 33, 35, 39, 45, 51, 52, 56, 58, 59, 66/68 and the low-risk (lr) HPV types include 6, 11, 40, 42, 43, 44, 26, 54, 61, 63, 73, 84, 81, 55. The exact binomial method was used to estimate $95 \%$ confidence interval (CI) of HPV infection, depicted by error bars. *In $x$-axis indicates significant differences $(p<0.05)$ between natural science and social science students, and first-and fourth-year students.

female student participants across the three cities - Hanoi, Hue and HCMC - are summarised in Table I. The mean age of female university students across the three Vietnamese cities was 19.8 years (range $=18-26$ years). Of the 1,491 students screened, HPV DNA was detected in 63 students: a prevalence of $4.2 \%$ (95\% CI=3.3\%-5.4\%). The prevalence of any hrHPV infection among the study population was $3.4 \%$ $(95 \% \mathrm{CI}=2.5 \%-4.4 \%)$ (Table I). The HPV prevalence by 

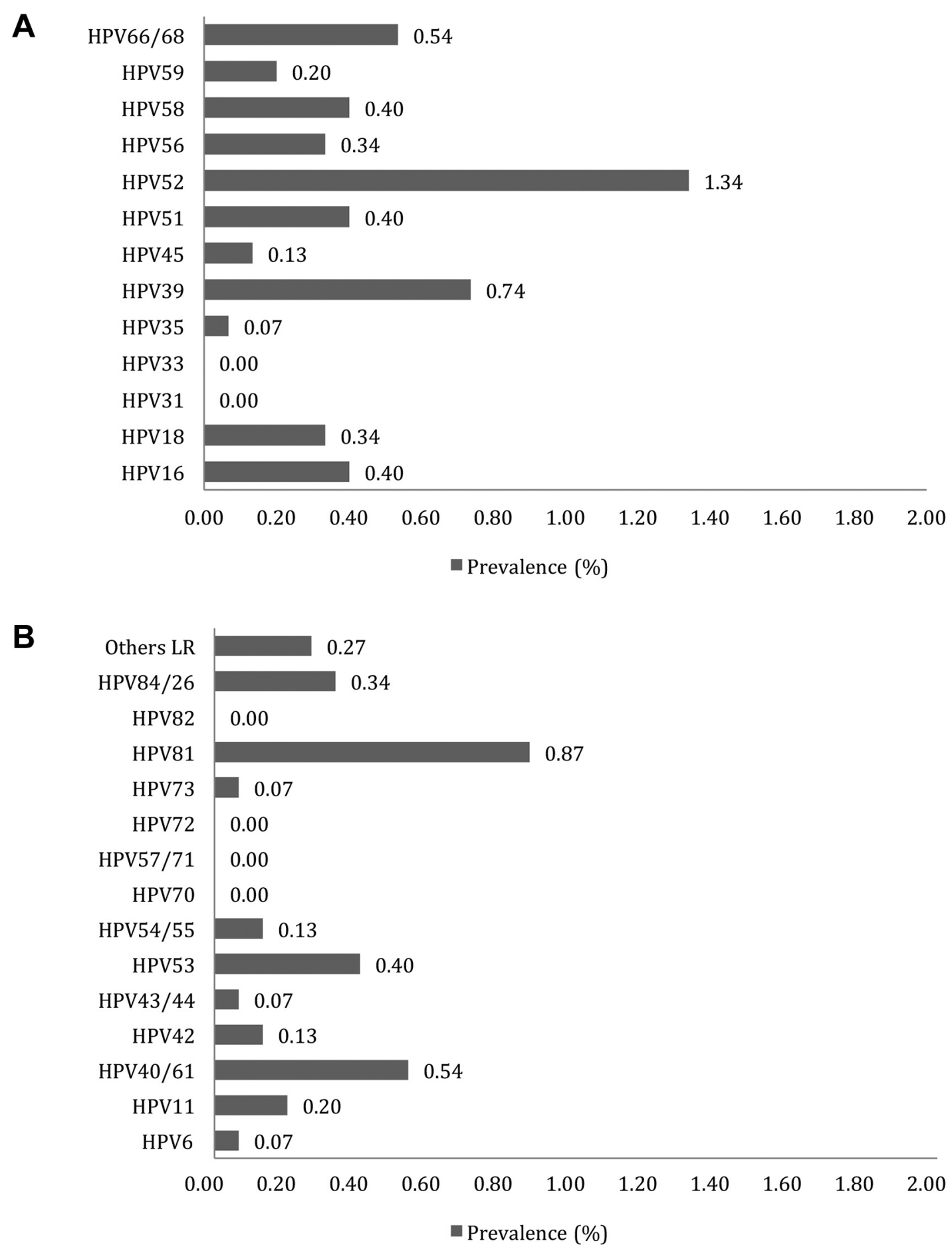

Figure 2. HPV genotype distribution among samples positives with high-(A) and low risk HPV types (B).

University departments, year level and cities are shown in Figure 1. There was little difference between the prevalence of any HPV and any hrHPV infection in Hanoi and Hue, where similar proportions of students studying natural and social sciences were recruited (Table I). Low HPV prevalence $(1.2 \%)$ was found for the university in HCMC, where there were only students from the Natural Science Department (Figure 1). 
Table II. Correlations of factors associated with high-risk HPV Infection.

\begin{tabular}{|c|c|c|c|c|c|c|}
\hline \multirow[b]{2}{*}{ Variables } & \multicolumn{4}{|c|}{ High-risk HPV Prevalence } & \multirow{2}{*}{$\frac{\text { Bivariate analysis }}{\text { PR }(95 \% \mathrm{CI})}$} & \multirow{2}{*}{$\frac{\text { Multivariate analysis }}{\operatorname{aPR}(95 \% \mathrm{CI})}$} \\
\hline & $\mathrm{N}$ & $\mathrm{n}$ & $\%$ & $p$-Value & & \\
\hline \multicolumn{7}{|l|}{ Study site } \\
\hline Hanoi & 492 & 20 & 4.1 & $<0.01$ & 1 & 1 \\
\hline Hue & 499 & 24 & 4.8 & & $1.19(0.66-2.15)$ & $0.86(0.46-1.59)$ \\
\hline Ho Chi Minh city & 500 & 6 & 1.2 & & $0.29(0.12-0.72)$ & $0.56(0.2-1.53)$ \\
\hline Age, in years & & & & & $1.36(1.14-1.62)$ & \\
\hline \multicolumn{7}{|l|}{ College field } \\
\hline Natural sciences & 981 & 18 & 1.8 & $<0.01$ & 1 & 1 \\
\hline Social sciences & 510 & 32 & 6.3 & & $3.5(1.96-6.23)$ & $2.16(1.09-4.27)$ \\
\hline \multicolumn{7}{|l|}{ Year of college } \\
\hline Year 1 & 738 & 17 & 2.3 & 0.03 & 1 & \\
\hline Year 4 & 753 & 33 & 4.4 & & $1.92(1.07-3.45)$ & \\
\hline Ever married & 5 & 1 & 20 & 0.157 & $6.62(0.91-47.94)$ & \\
\hline \multicolumn{7}{|l|}{ Living arrangements } \\
\hline With family & 511 & 13 & 2.5 & 0.187 & 1 & \\
\hline With friends & 814 & 28 & 3.4 & & $1.36(0.7-2.62)$ & \\
\hline Alone & 166 & 9 & 5.4 & & $2.16(0.92-5.06)$ & \\
\hline Ever smoked & 26 & 2 & 7.7 & 0.216 & $2.4(0.58-9.86)$ & $1.26(0.29-5.41)$ \\
\hline Ever consumed alcohol & 1011 & 43 & 4.3 & $<0.01$ & $3.39(1.44-7.96)$ & $1.92(0.85-4.33)$ \\
\hline Ever had sex & 202 & 29 & 14.4 & $<0.01$ & $9.39(5.36-16.47)$ & $6.22(3.4-11.37)$ \\
\hline Inconsistent contraceptive use & 107 & 14 & 13.1 & 0.689 & $0.82(0.39-1.69)$ & \\
\hline Inconsistent condom use & 53 & 8 & 15.1 & 1 & $1.03(0.43-2.45)$ & \\
\hline Ever been pregnant & 12 & 6 & 50 & $<0.01$ & $4.74(1.64-13.69)$ & $4.82(1.93-12.04)$ \\
\hline Ever given birth & 4 & 1 & 25 & 1 & $0.58(0.07-4.78)$ & \\
\hline Ever had abortion & 9 & 5 & 55.6 & 0.096 & $3.07(0.93-10.09)$ & \\
\hline Ever had any gynaecological infections & 242 & 18 & 7.4 & $<0.01$ & $2.97(1.67-5.3)$ & \\
\hline Ever had HPV vaccines & 68 & 0 & 0 & 0.167 & & \\
\hline Family history of HPV infection & 26 & 0 & 0 & 1 & & \\
\hline Ever hear of HPV before this study & 1,097 & 42 & 3.8 & 0.103 & $1.9(0.89-4.04)$ & \\
\hline Ever hear of HPV vaccinations before this study & 917 & 31 & 3.4 & 1 & $1.01(0.57-1.8)$ & \\
\hline
\end{tabular}

PR: Prevalence ratio; aPR: adjusted prevalence ratio.

HPV genotype distribution. Twelve high-risk HPV types were found in our cohort (Figure 2); HPV31 and 33 were not detected. HPV52 represents the most common HPV type detected (31.8\% of positive samples), followed by HPV39 $(17.5 \%)$, representing a prevalence of $1.34 \%$ (20/1491) and $0.74 \%$ (11/1491) for HPV52 and HPV39 respectively. Among the low-risk HPV types, HPV81 was the dominant type, accounting for $20.6 \%$ of positive samples (prevalence $0.87 \%)$. Multiple HPV types were found in $33(52 \%)$ of the positive samples. Mixed hrHPV and lrHPV infection were found in 25 of them with as many as five types found in some samples. Thirty-seven students (15 in Hanoi, 15 in Hue and seven in HCMC) who reported never having had sex were positive with HPV. Among these, 10 individuals were infected with only low-risk types, and 27 individuals were infected with hrHPV including multiple infections with HPV16, HPV39, HPV52 and HPV56 being the most commonly detected in up to 8 individuals. One individual was co-infected with HPV18, HPV39 and HPV58. No abnormal cytology was found in students who were infected with HPV16 or HPV18. Sixty-eight (4.6\%) students who had HPV vaccine were not infected with HPV.

Risk factors for HPV infection. Being older was associated with higher prevalence of HPV infection $(p=0.029)$ (Table II), including hrHPV infections (adjusted prevalence ratio, $\mathrm{aPR}=1.92,95 \% \mathrm{CI}=1.07-3.45, \quad p=0.03)$. Acquiring $\mathrm{HPV}$ infection was more likely to be associated with students from the social sciences discipline (aPR, 2.16, 95\%CI=1.09-4.27 when compared to age-matched natural science students) and those who have had sex (aPR, 6.22; 95\%CI=3.4-11.37) (Table II). Having ever been pregnant was also positively associated with HPV infection (aPR, 4.82; 95\%CI=1.93-12.04) (Table II). Knowledge of HPV and cervical cancer. More than half of the study participants had heard about HPV and HPV vaccination $(73.6 \%$ and $61.5 \%$, respectively), but less than $5 \%$ of participants were vaccinated (Figure 3 ). Final year students had higher HPV knowledge $(81.0 \%)$ than first-year 


\section{HPV Knowledge}

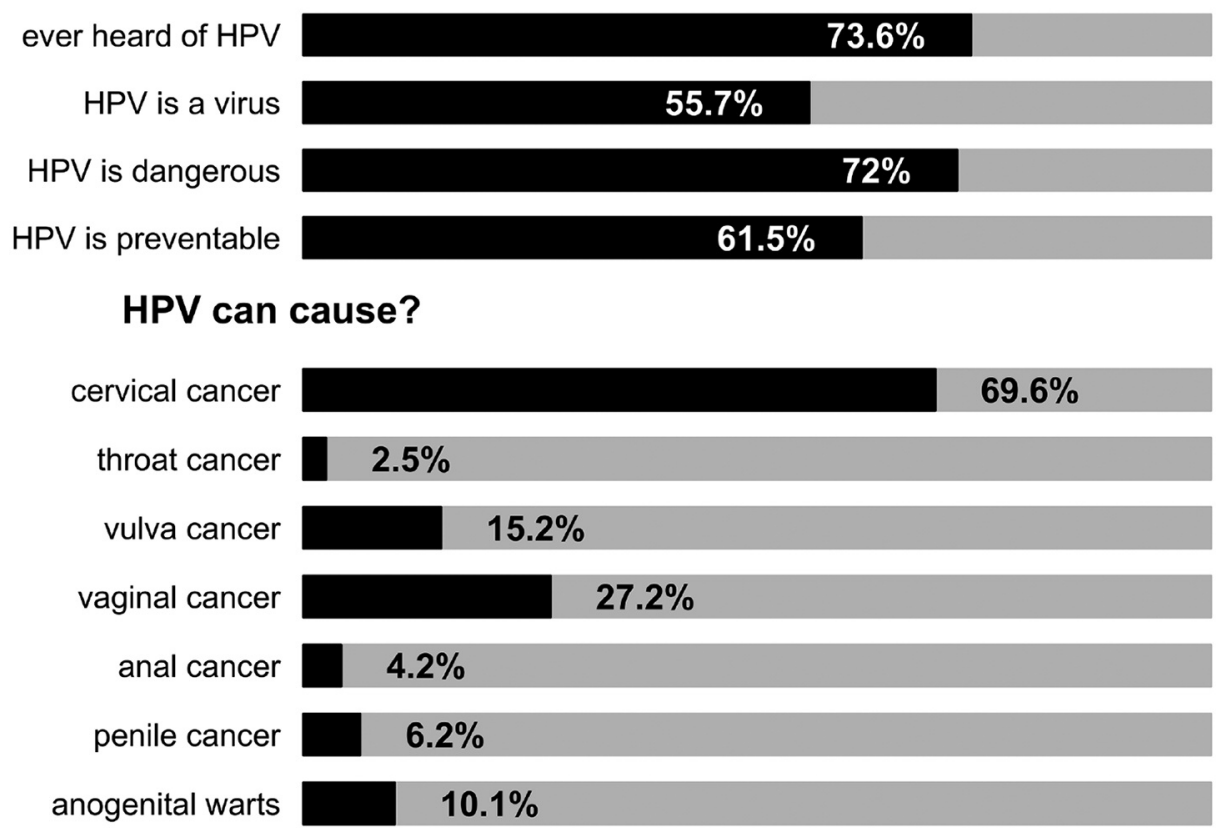

\section{Cervical Cancer Knowledge}

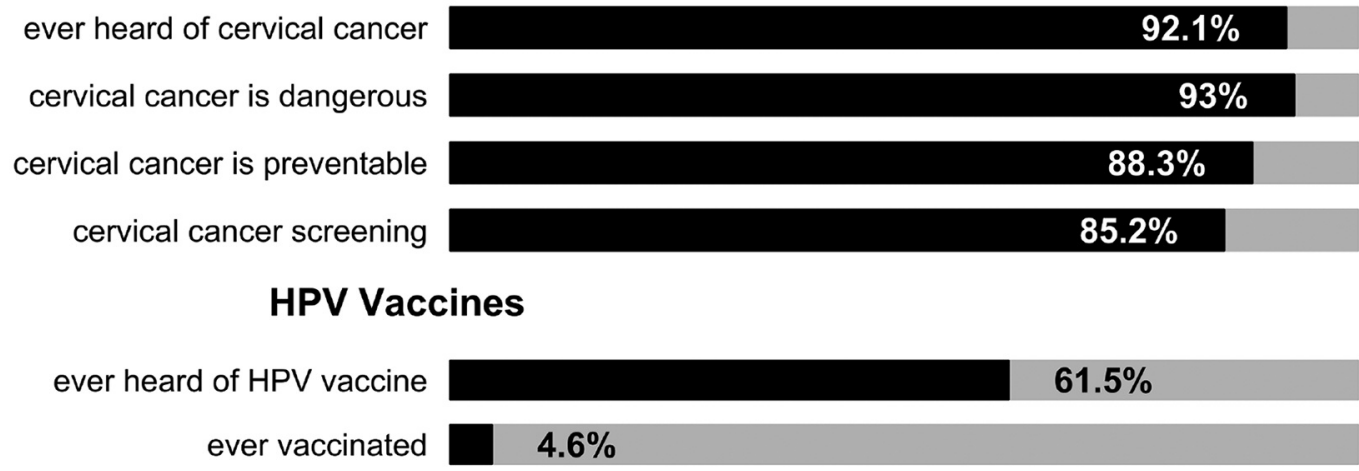

Figure 3. HPV and cervical cancer knowledge among female university students in Hanoi, Hue, and Ho Chi Minh City, 2017-2019.

students $(59.2 \%)$. However, the majority of students were not aware that HPV causes anogenital cancers and anogenital warts other than cervical cancer.

\section{Discussion}

In the largest HPV prevalence study among young female university students aged 18-26 years old in Vietnam, we found a low prevalence of any HPV infection, including hrHPV, in Hanoi, Hue, and HCMC. This finding contrasts with studies in other countries. For example, Oh et al. found a higher prevalence of HPV infection (17.5\%) among South Korean students aged 17 to 26 years (20). Among the identified HPV types, they reported HPV16, 18 and 35 were the most common and HPV infection was associated with sexual debut, new sexual partners, and smoking (20). Studies in the United States have reported HPV prevalence rates of $19.7 \%$ to $44.8 \%$ among female university students, depending on their age (11, 21). In the study by Forhan et al., among 838 American women aged 14 to 19 years, the HPV-positive rate was $18.3 \%$ (22). In Brazil, Vieira et al. found that $25.3 \%$ of students aged 25 years old were infected with HPV (23). In Greece, HPV prevalence of $40-70 \%$ were observed among young women aged 18-26 years from outpatient clinics during 2011-2016 with HPV16 and 31 being the most common genotypes (24). According to Institute Catala d'Oncologia, the median age of 
Vietnamese women at first sexual intercourse ranged from 21.0 to 21.5 years old, corresponding to third or final year in university (25). The low HPV prevalence observed in our study population could be attributed to the low sexual activity/initiation in this age group in comparison to other populations in the studies mentioned above in Korea $(21 \%)$, Brazil (>75\%), USA (61.4\%-73.2\%). Given the low prevalence of HPV infection among female university students in Vietnam observed in our study, HPV vaccination will protect them from acquiring oncogenic HPV genotypes, particularly HPV16 and 18. We found the prevalence of hrHPV infections was not different in the three Vietnamese cities. However, hrHPV infections were more prevalent among students from the Social Sciences Department in Hanoi and Hue when compared to the Natural Sciences Department in all three cities. One potential factor of the difference in HPV prevalence between the departments may be a reflection of differences in sexual behaviour in social science students in our cohort compared to natural science students.

While most participants know about cervical cancer and more than half had heard about HPV vaccines, only $4.6 \%$ of the cohort had been vaccinated. High vaccine costs, accessibility and lack of knowledge regarding HPV and the benefits of the vaccine are likely to be the main barriers to HPV vaccine uptake in Vietnam $(26,27)$. A 2016 study of 932 college students by Kamimura et al. (495 in Vietnam and 437 in the United States) found that Vietnamese participants had lower levels of knowledge about HPV, more barriers to HPV vaccination (i.e., costs and stigma associated with HPV vaccination) and higher levels of risk denial compared to United States participants. In that study, the percentage of Vietnamese participants who were vaccinated with HPV $(7.5 \%)$ was much lower than the participants from the United States (42\%) (26). There is a need to improve access to HPV vaccine and sexual health education, including benefits of HPV vaccination in this population.

The dominant HPV52 genotype in our study is similar to previous studies in Vietnam and other parts of Asia for example Japan $(28,29)$. HPV58 and 59, which were the common genotypes in other studies in Vietnam, represented $8 \%$ and $4 \%$ respectively among the hrHPV genotypes in our study (28). It is important to note that HPV52 and 58 are responsible for a significant proportion of cervical cancer in Asia. We identified HPV 39 and 66/68 the second and third most common hrHPV genotypes in our cohort. HPV 39 has been found to be one of the most prevalent HPV genotypes in women in rural areas in Bolivia, Nepal and China (30-32), while HPV 66 was found to be prevalent in Korea, Brazil and Mexico (33-35). Notably, these genotypes except HPV52 and 58 are not present in all licensed HPV vaccines. This finding warrants ongoing surveillance of HPV disease caused by these HPV types, which may be important for future HPV vaccine development.
Effective primary and secondary preventions - HPV vaccination and cytology screening - have shown promise in eliminating cervical cancer $(26,36,37)$. Early vaccine impact on anogenital warts is demonstrated in some highincome settings where vaccination was introduced in young adolescents $(8,38,39)$. The risk of cervical cancer remains high in many LMICs such as Vietnam because of the absence of routine HPV vaccination and effective cervical screening programmes $(28,29)$. Most LMICs are challenged with financial and logistic constraints, such as the availability of healthcare infrastructure to implement cervical screening at high coverage $(7,8)$, high costs of HPV vaccine, the ability to acquire adequate vaccine supplies, and the feasibility of reaching high coverage when vaccinating individuals outside infant vaccination schedules.

Our study demonstrated the feasibility of self-swab in HPV screening in Vietnam. More than $98 \%$ of samples from each site were valid for further HPV screening, indicated by the presence of HLA internal control. This collection method would facilitate the HPV screening nationwide allowing for HPV screening with high precision assays, an important component of the HPV related cancer reduction program.

The challenges of a multi-site study include logistical and personnel coordination as well as the standardisation of all study procedures including laboratory testing across different sites. These were mostly overcome by regular meetings between the study groups, rigourous study procedures and well-considered study design. Nevertheless, our study has several limitations. First, our study is based around university students in Hanoi, Hue and HCMC and may not be generalizable to out-of-school females and the whole of Vietnam. Second, no social science students were recruited from HCMC, and this led to potential bias in estimating sexual behaviours and HPV prevalence among female students across the three study cities. Third, culturally, female student participants may under-report socially undesirable behaviours such as their sexual activities, as indicated by the presence of HPV in individuals who reported never having had sexual activity. Last, our recruitment method was calling for volunteers to participate which may have led to participant bias.

\section{Conclusion}

In this cross-sectional, multi-site study in Vietnam, we identified a low HPV prevalence rate and low HPV vaccination coverage among female university students. Our study highlighted the potential benefit of a national HPV vaccination program and the need for a health promotion program addressing HPV knowledge in rolling out a vaccine program for young females in Vietnam. 


\section{Conflicts of Interest}

The Authors have declared no competing interest.

\section{Authors' Contributions}

KM and NVT conceptualised the study. KM, NVT, SMG, DDA, QDP and HPT contributed to study design. QDP, BTVH, KVN and PTNL were involved in data collection. DTL, LTKL, VC and TDLH screened and genotyped the samples in the laboratory. KP, MJ, MB, $\mathrm{KB}$, QDP, and NVT contributed to statistical analysis and made the figures. KP, ZQT and NVT did the literature review. KP, NVT and MJ wrote the initial draft. All Authors contributed to data interpretation, critically reviewed the manuscript and approved the final version.

\section{Acknowledgements}

The authors would like to thank the study participants and staff of the Vietnam National University in Hanoi, Hue and in Ho Chi Minh City for their involvement with this study. This work was supported by the UK Medical Research Council (MRC), and Vietnamese Ministry of Science and Technology as part of the UK-Vietnam Research Collaboration (Newton Fund), project number HNQT/SPDP/03.16.

\section{References}

1 Crosbie EJ, Einstein MH, Franceschi $\mathrm{S}$ and Kitchener HC: Human papillomavirus and cervical cancer. Lancet 382(9895): 889-899, 2013. PMID: 23618600. DOI: $10.1016 / \mathrm{S} 0140-$ 6736(13)60022-7

2 Moscicki AB, Palefsky J, Smith G, Siboshski S and Schoolnik G: Variability of human papillomavirus DNA testing in a longitudinal cohort of young women. Obstet Gynecol 82(4 Pt 1): 578-585, 1993. PMID: 8397358.

3 Hildesheim A, Schiffman MH, Gravitt PE, Glass AG, Greer CE, Zhang T, Scott DR, Rush BB, Lawler P and Sherman ME: Persistence of type-specific human papillomavirus infection among cytologically normal women. J Infect Dis 169(2): 235240, 1994. PMID: 8106758. DOI: 10.1093/infdis/169.2.235

4 Richardson H, Kelsall G, Tellier P, Voyer H, Abrahamowicz M, Ferenczy A, Coutlée F and Franco EL: The natural history of type-specific human papillomavirus infections in female university students. Cancer Epidemiol Biomarkers Prev 12(6): 485-490, 2003. PMID: 12814991.

5 Sycuro LK, Xi LF, Hughes JP, Feng Q, Winer RL, Lee SK, O'Reilly S, Kiviat NB and Koutsky LA: Persistence of genital human papillomavirus infection in a long-term follow-up study of female university students. J Infect Dis 198(7): 971-978, 2008. PMID: 18694334. DOI: $10.1086 / 591625$

6 de Sanjose S, Quint WG, Alemany L, Geraets DT, Klaustermeier JE, Lloveras B, Tous S, Felix A, Bravo LE, Shin HR, Vallejos CS, de Ruiz PA, Lima MA, Guimera N, Clavero O, Alejo M, LlombartBosch A, Cheng-Yang C, Tatti SA, Kasamatsu E, Iljazovic E, Odida M, Prado R, Seoud M, Grce M, Usubutun A, Jain A, Suarez GA, Lombardi LE, Banjo A, Menéndez C, Domingo EJ, Velasco J, Nessa A, Chichareon SC, Qiao YL, Lerma E, Garland SM, Sasagawa T, Ferrera A, Hammouda D, Mariani L, Pelayo A, Steiner I, Oliva E, Meijer CJ, Al-Jassar WF, Cruz E, Wright TC, Puras A, Llave CL, Tzardi M, Agorastos T, Garcia-Barriola V, Clavel C, Ordi
J, Andújar M, Castellsagué X, Sánchez GI, Nowakowski AM, Bornstein J, Muñoz N, Bosch FX and Retrospective International Survey and HPV Time Trends Study Group: Human papillomavirus genotype attribution in invasive cervical cancer: a retrospective cross-sectional worldwide study. Lancet Oncol 11(11): 1048-1056, 2010. PMID: 20952254. DOI: 10.1016/S1470-2045(10)70230-8

7 Cuzick J, Arbyn M, Sankaranarayanan R, Tsu V, Ronco G, Mayrand $\mathrm{MH}$, Dillner J and Meijer CJ: Overview of human papillomavirusbased and other novel options for cervical cancer screening in developed and developing countries. Vaccine 26(Suppl 10): K29K41, 2008. PMID: 18847555. DOI: 10.1016/j.vaccine.2008.06.019

8 Simms KT, Steinberg J, Caruana M, Smith MA, Lew JB, Soerjomataram I, Castle PE, Bray F and Canfell K: Impact of scaled up human papillomavirus vaccination and cervical screening and the potential for global elimination of cervical cancer in 181 countries, 2020-99: a modelling study. Lancet Oncol 20(3): 394-407, 2019. PMID: 30795950. DOI: 10.1016/ S1470-2045(18)30836-2

9 Human papillomavirus vaccines: WHO position paper, October 2014. Wkly Epidemiol Rec 89(43): 465-491, 2014. PMID: 25346960.

10 World Health Organization: Who leads the way towards the elimination of cervical cancer as a public health concern. World Health Organization, 2018.

11 Winer RL, Lee SK, Hughes JP, Adam DE, Kiviat NB and Koutsky LA: Genital human papillomavirus infection: incidence and risk factors in a cohort of female university students. Am J Epidemiol 157(3): 218-226, 2003. PMID: 12543621. DOI: 10.1093/aje/kwf180

12 Ferrera A, Tábora N, Flores Y, Zelaya A, Massuger L and Melchers WJ: Assessment of HPV infection among female university students in Honduras via Roche linear array. Int J Gynaecol Obstet 113(2): 96-99, 2011. PMID: 21345434. DOI: 10.1016/j.ijgo.2010.11.016

13 Bray F, Ferlay J, Soerjomataram I, Siegel RL, Torre LA and Jemal A: Global cancer statistics 2018: GLOBOCAN estimates of incidence and mortality worldwide for 36 cancers in 185 countries. CA Cancer J Clin 68(6): 394-424, 2018. PMID: 30207593. DOI: $10.3322 /$ caac. 21492

14 Nguyen TP, Luu HN, Nguyen MVT, Tran MT, Tuong TTV, Tran CTD and Boffetta P: Attributable causes of cancer in Vietnam. JCO Glob Oncol 6: 195-204, 2020. PMID: 32045545. DOI: 10.1200/JGO.19.00239

15 Van Minh H, My NTT and Jit M: Cervical cancer treatment costs and cost-effectiveness analysis of human papillomavirus vaccination in Vietnam: a PRIME modeling study. BMC Health Serv Res 17(1): 353, 2017. PMID: 28506297. DOI: 10.1186/ s12913-017-2297-x

16 Houlihan CF, Baisley K, Bravo IG, Kapiga S, de Sanjosé S, Changalucha J, Ross DA, Hayes RJ and Watson-Jones D: Rapid acquisition of HPV around the time of sexual debut in adolescent girls in Tanzania. Int J Epidemiol 45(3): 762-773, 2016. PMID: 26944311. DOI: 10.1093/ije/dyv367

17 Woodman CB, Collins S, Winter H, Bailey A, Ellis J, Prior P, Yates M, Rollason TP and Young LS: Natural history of cervical human papillomavirus infection in young women: a longitudinal cohort study. Lancet 357(9271): 1831-1836, 2001. PMID: 11410191. DOI: 10.1016/S0140-6736(00)04956-4

18 Franceschi S, Herrero R, Clifford GM, Snijders PJ, Arslan A, Anh PT, Bosch FX, Ferreccio C, Hieu NT, Lazcano-Ponce E, Matos 
E, Molano M, Qiao YL, Rajkumar R, Ronco G, de Sanjosé S, Shin HR, Sukvirach S, Thomas JO, Meijer CJ and Muñoz N: Variations in the age-specific curves of human papillomavirus prevalence in women worldwide. Int J Cancer 119(11): 26772684, 2006. PMID: 16991121. DOI: 10.1002/ijc.22241

19 World Health Organization: Human papillomavirus laboratory manual. 1st edn. World Health Organization, 2010. Available at: https://www.who.int/immunization/hpv/learn/hpv_laboratory_manu al_who_ivb_2009_2010.pdf [Last accessed on October 1, 2021]

20 Oh JK, Ju YH, Franceschi S, Quint W and Shin HR: Acquisition of new infection and clearance of type-specific human papillomavirus infections in female students in Busan, South Korea: a follow-up study. BMC Infect Dis 8: 13, 2008. PMID: 18234114. DOI: $10.1186 / 1471-2334-8-13$

21 Liddon NC, Leichliter JS and Markowitz LE: Human papillomavirus vaccine and sexual behavior among adolescent and young women. Am J Prev Med 42(1): 44-52, 2012. PMID: 22176845. DOI: 10.1016/j.amepre.2011.09.024

22 Forhan SE, Gottlieb SL, Sternberg MR, Xu F, Datta SD, McQuillan GM, Berman SM and Markowitz LE: Prevalence of sexually transmitted infections among female adolescents aged 14 to 19 in the United States. Pediatrics 124(6): 1505-1512, 2009. PMID: 19933728. DOI: 10.1542/peds.2009-0674

23 Vieira RC, Monteiro Jdo S, Manso EP, Dos Santos MR, Tsutsumi MY, Ishikawa EA, Ferrari SF, Lima KV and de Sousa MS: Prevalence of type-specific HPV among female university students from northern Brazil. Infect Agent Cancer 10: 21, 2015. PMID: 26203300. DOI: 10.1186/s13027-015-0017-x

24 Argyri E, Tsimplaki E, Papatheodorou D, Daskalopoulou D and Panotopoulou E: Recent trends in HPV infection and type distribution in Greece. Anticancer Res 38(5): 3079-3084, 2018. PMID: 29715143. DOI: 10.21873/anticanres.12565

25 Bruni L, Albero G, Serrano B, Mena M, Gomez D, Munoz J, Bosch FX and de Sanjose S: Ico/iarc information center on hpv and cancer. Human papillomavirus and related diseases in Vietnam. Summary report 17 june 2019. HPV information center, 2019. Available at: https://hpvcentre.net/statistics/reports/ VNM.pdf?t=1633079905688 [Last accessed on October 1, 2021]

26 Kamimura A, Trinh HN, Weaver S, Chernenko A, Wright L, Stoddard M, Nourian MM and Nguyen H: Knowledge and beliefs about HPV among college students in Vietnam and the United States. J Infect Public Health 11(1): 120-125, 2018. PMID: 28668657. DOI: 10.1016/j.jiph.2017.06.006

27 Tran BX, Than PTQ, Doan TTN, Nguyen HLT, Thi Mai H, Nguyen THT, Le HT, Latkin CA, Zhang MW and Ho RC: Knowledge, attitude, and practice on and willingness to pay for human papillomavirus vaccine: a cross-sectional study in Hanoi, Vietnam. Patient Prefer Adherence 12: 945-954, 2018. PMID: 29881260. DOI: 10.2147/PPA.S165357

28 Van SN, Khac MN, Dimberg J, Matussek A and Henningsson AJ: Prevalence of cervical infection and genotype distribution of human papilloma virus among females in Da Nang, Vietnam. Anticancer Res 37(3): 1243-1247, 2017. PMID: 28314288. DOI: 10.21873/anticanres. 11440

29 Imai H, Nakao H, Shinohara H, Watarai M, Matsumoto N, Yamagishi T, Saito M and Kitamura T: Prevalence, potential predictors, and genotype-specific prevalence of human papillomavirus infection among sexually active students in Japan. PLoS One 10(7): e0132462, 2015. PMID: 26176861. DOI: $10.1371 /$ journal.pone.0132462
30 Patzi-Churqui M, Terrazas-Aranda K, Liljeqvist JÅ, Lindh M and Eriksson K: Prevalence of viral sexually transmitted infections and HPV high-risk genotypes in women in rural communities in the Department of La Paz, Bolivia. BMC Infect Dis 20(1): 204, 2020. PMID: 32143643. DOI: 10.1186/s12879-020-4931-1

31 Thapa N, Maharjan M, Shrestha G, Maharjan N, Petrini MA, Zuo N, He C, Yang J, Xu M, Ge C, Song Z and Cai H: Prevalence and type-specific distribution of human papillomavirus infection among women in mid-western rural, Nepal- A population-based study. BMC Infect Dis 18(1): 338, 2018. PMID: 30029626. DOI: 10.1186/s12879-018-3175-9

32 Baloch Z, Yasmeen N, Li Y, Ma K, Wu X, Yang SH and Xia X: Prevalence and risk factors for human papillomavirus infection among Chinese ethnic women in southern of Yunnan, China. Braz J Infect Dis 21(3): 325-332, 2017. PMID: 28284657. DOI: 10.1016/j.bjid.2017.01.009

33 Park E, Kim JY, Choi S, Kim DS and Oh YL: Carcinogenic risk of human papillomavirus (HPV) genotypes and potential effects of HPV vaccines in Korea. Sci Rep 9(1): 12556, 2019. PMID: 31467383. DOI: 10.1038/s41598-019-49060-w

34 Batista JE, Saddi VA, Carvalho KPA, Ribeiro AA, Segati KD, Carneiro MADS, Monteiro SG, Nascimento MDDSB and Rabelo-Santos SH: Human papillomavirus genotypes 68 and 58 are the most prevalent genotypes in women from quilombo communities in the state of Maranhão, Brazil. Int J Infect Dis 55: 51-55, 2017. PMID: 28088590. DOI: 10.1016/j.ijid.2017.01.001

35 Juárez-González K, Paredes-Cervantes V, Gordillo-Rodríguez S, González-Guzmán S, Moncayo-Valencia X, Méndez-Martínez R, García-Carrancá A, Martínez-Ezquerro JD, Rivas-Ruiz R, Sánchez-Suárez P, Álvarez-Sandoval P, Padilla-Arrieta P, Martínez-Salazar M and Vázquez-Vega S: High prevalence of human papillomavirus type 66 in low-grade cervical lesions of Mexican women. Arch Virol 165(11): 2633-2640, 2020. PMID: 32812092. DOI: $10.1007 / \mathrm{s} 00705-020-04771-8$

36 Clifford GM, Gallus S, Herrero R, Muñoz N, Snijders PJ, Vaccarella S, Anh PT, Ferreccio C, Hieu NT, Matos E, Molano M, Rajkumar R, Ronco G, de Sanjosé S, Shin HR, Sukvirach S, Thomas JO, Tunsakul S, Meijer CJ, Franceschi S and IARC HPV Prevalence Surveys Study Group: Worldwide distribution of human papillomavirus types in cytologically normal women in the International Agency for Research on Cancer HPV prevalence surveys: a pooled analysis. Lancet 366(9490): 991-998, 2005. PMID: 16168781. DOI: 10.1016/S0140-6736(05)67069-9

37 Dunne EF, Unger ER, Sternberg M, McQuillan G, Swan DC, Patel SS and Markowitz LE: Prevalence of HPV infection among females in the United States. JAMA 297(8): 813-819, 2007. PMID: 17327523. DOI: 10.1001/jama.297.8.813

38 Lei J, Ploner A, Elfström KM, Wang J, Roth A, Fang F, Sundström K, Dillner J and Sparén P: HPV vaccination and the risk of invasive cervical cancer. N Engl J Med 383(14): 13401348, 2020. PMID: 32997908. DOI: 10.1056/NEJMoa1917338

39 Ali H, Donovan B, Wand H, Read TR, Regan DG, Grulich AE, Fairley CK and Guy RJ: Genital warts in young Australians five years into national human papillomavirus vaccination programme: national surveillance data. BMJ 346: f2032, 2013. PMID: 23599298. DOI: 10.1136/bmj.f2032

Received August 16, 2021

Revised September 20, 2021

Accepted October 1, 2021 